\title{
Penggunaan Kamus Musa'id Lil Arabiyah Baina Yadaik Sebagai Media Pembelajaran Bahasa Arab Mahasiswi Semester Satu STAI AS-SUNNAH Medan Tahun Ajaran 2019
}

\author{
Kaamiliyah Fathanah ${ }^{1}$, Sulton Bigadaran ${ }^{2}$, Nur Hasan ${ }^{3}$, Wildana Wargadinata ${ }^{4}$ \\ ${ }^{1,2,3,4}$ Universitas Islam Negeri Maulana Malik Ibrahim Malang, Indonesia \\ E-mail: ${ }^{1}$ kaamiliyah.fathanah@gmail.com, ${ }^{2}$ Sbigadaran88@gmail.com, ${ }^{3}$ nur.hasan@unisma.ac.id, \\ ${ }^{4}$ wargadi@gmail.com
}

\begin{abstract}
Abstrak : Belajar bahasa merupakan kegiatan yang tidak terlepas dari penggunaan kamus untuk menunjang proses pembelajaran, Kamus adalah salah satu alat bantu dalam memahami suatu bahasa, yang disertai dengan terjemah dan digunakan untuk meningkatkan kemampuan dalam berbahasa asing, begitupun dengan bahasa arab. STAI As-Sunnah Medan telah menerapkan penggunaan kamus musai'd lil kitab baina yadaik ketika proses pembelajaran bahasa arab khususnya pada mahasiwi semester satu yang menggunakan buku panduan AlArabiyah baina yadaik. Kamus musa'id lil kitab baina yadaik bisa dikatagorikan kedalam kamus buku atau mu'jam al-kitaab yakni kamus yang kata-katanya disusun secara tematik berdasarkan penyusunan buku tertentu. Dari pernyataan tersebut bisa dikatakan bahwasannya kamus musa'id lilkitab baina yadaik adalah kamus buku karena kamus ini disusun berdasarkan makna dan sesuai dengan bab-bab yang di tulis dalam buku Al-Arabiyah bainna yadaik. Kamus musa'id lil kitab baina yadaik juga dijadikan media pembelajaran dalam pembelajaran bahasa arab di Stai As-Sunnah Medan serta penolong bagi para mahasiswi untuk mempermudah memahami buku al-arabiyah baina yadaik dan belajar bahasa arab. Kamus Musaid Al Arabiyah Baina Yadaik juga mencakup terjemahan dari kosa kata sulit yang terdapat pada buku Al Arabiyah Baina Yadaik sesuai dengan tema yang dibahas.
\end{abstract}

Abstract : Learning a language is an activity that cannot be separated from the use of a dictionary to support the process, a dictionary is a tool in understanding a language, accompanied by a translation and used to improve foreign language skills, as well as Arabic. STAI As-Sunnah Medan has implemented the use of the musai'd lil Kitab baina yadaik dictionary during the Arabic language learning process, especially for first semester students who use the baina yadaik Al-Arabiyah manual. The musa'id lil Kitab baina yadaik dictionary can be categorized into a book dictionary or mujam al-kitaab, which is a dictionary whose words are arranged thematically based on the arrangement of certain books. From this statement, it can be said that the musa'id lilkitab baina yadaik dictionary is a book dictionary because it is compiled based on meaning and following the articles written in the al-Arabiyah bainna yadaik book. The musa'id lil Kitab baina yadaik dictionary is also used as a medium of learning in learning Arabic at Stai As-Sunnah Medan and as a helper for students to make it easier to understand the Kitab al-arabiyah baina yadaik and learn Arabic. The Baina Yadaik Musaid Al Arabiyah Dictionary also contains translations of difficult words contained in the Baina Yadaik Al Arabiyah book according to the themes discussed.

Kata kunci: Bahasa Arab; Kamus Musaid lil kitab Al-Arobiyah Baina Yadaik dan Media Pembelajaran 


\section{PENDAHULUAN}

Secara umum bahasa ada kaitannya dengan pola pikir maupun budaya dari sebuah masyarakat. Sehingga bahasa bisa tersampaikan dengan pola pikor pada setiap orang melalui lisannya sendiri secara sadar. Maka dengan adanya bahasa ini, terjadilah pewarisan budaya secara turun temurun. Bahasa juga adalah sebuah bunyi yang tersistem dan memiliki urutan vokal terstruktur (tersusun). Yang dapat digunakan untuk berkomunikasi secara internasional, Bahasa juga digunakan untuk mengungkapkan suatu kejadian atau keadaan yang ada di sekitar manusia. Dengan menyadari pentingnya bahasa sebagai alat berkomunikasi maka ada baiknya kita juga mempelajari bahasa asing dan tidak hanya berfokus pada bahasa ibu saja.

Salah satu bahasa yang cukup banyak diminati diindonesia salah satunya adalah bahasa arab, khususnya bagi para pelajar muslim yang berkeinginan untuk melajutkan pendidikan ke negara timur tengah, dan pelajar yang ingin memperdalam pemahaman agama. Bukan hanya sebagai bahasa yang digunakan oleh agama islam saja bahasa arab juga dijadikan sebagai salah satu bahasa internasional yang digunakan masyarakat di berbagai negara. Bahasa arab merupakan bahan ajar yang diwajibkan di lembaga pendidikan islam, baik itu tingkat pendidikan ibtidaiyah, tsanawiyah, maupun aliyah bahkan diperguruan tinggi sekalipun. Jadi bisa dikatakan bahwasannya pembelajara bahasa arab di Indonesia bukanlah hal yang tabu, karena sedikit banyaknya bahasa arab sudah diajarkan di sekolah.

Sebagaimana pelajaran pada umumnya pembelajaran bahasa arab juga membutuhkan alat yang bisa digunakan untuk menunjang agar proses pembelajaran bisa berjalan maksimal salah satu komponennya adalah media pmbelajaran, menurut Gerlanc, secara umum media meliputi orang, peralatan, bahan atau suatu kegiatan yang membuat keadaan peserta didik mendapatkan pengetahuan, keterampilan dan sikap. ${ }^{1}$ Dari penjelasan diatas penulis menyimpulkan bahwasannya media pembelajaran yaitu orang maupun alat yang memudahkan siswa untuk mendapatkan informasi baik itu berupa ilmu, keterampilan, dankemampuandalam bersikap. Dengan menggunakan media pembelajaran maka proses pembelajaran akan menjadi lebih mudah difahami, dimengerti dan di terapkan.

Berbicara mengenai media pembelajaran yang digunakan untuk pembelajaran bahasa Arab, di kota medan terdapat sebuah Sekolah Tinggi Agama Islam As-Sunah, merupakan salah satu perguruan tinggi swasta yang didalamnya terdapat dua jurusan yaitu pendidikan bahasa Arab dan komunikasi penyiaran agama islam untuk mahasiswa dan mahasiswinya. Namun dalam penulisan ini penulis akan berfokus pada pendidikan bahasa Arab saja. Pada jurusan pendidikan bahasa Arab, mahasiswa dan mahasiswi menggunakan rujukan dari bukubuku yang berbahasa bahasa Arab. Hal yang menarik menurut hasil tinjauan peneliti bahwa di STAI As-sunnah menggunakan buku bahasa Arab al-arabiyah baina yadiak sebagai buku rujukan dalam pembelajaran bahasa Arab, dan menggunakan salah satu kamus kecil yang bernama musaid lil kitaab baina yadaik. Yang mana kamus ini dijadikan sebagai salah satu media pembelajaran dalam penyampaian materi perkuliahan pembelajaran bahasa Arab. Kamus ini dianggap sebagai salah satu perantara yang bisa memudahkan dosen untuk mengajarkan materi perkuliahan bahasa Arab Dan memudahkan para mahasiswa dan mahasiswi untuk mengikuti dan memahami materi perkuliahan dengan adanya kamus musai'd lil kitab baina yadaik.

\footnotetext{
${ }^{1}$ Muh Arif dan Eby Waskino Makalalag, Pengembangan Media Pembelajaran Bahasa Arab (Padang: Balai Insan Cendekia Mandiri, 2020), 3.
} 


\section{METODE}

Jenis penelitian yang digunakan dalam penelitian ini adalah deskriptif, karena maksud dari penelitian ini adalah untuk menggambarkan fenomena-fenomena yang sedang terjadi ataupun yang sudah berlalu, penelitian deskristif ini dapat menggambarkan suatu keadaan maupun tahapan-tahapan suatu objek penelitian. ${ }^{2}$

Penelitian ini termasuk kedalam penelitian kulitataif, sebagaimana Bogdan dan taylor mendefenisikan kualitatif sebagai prosedur penelitian untuk mendapatkan data deskriptif berupa kata-kata ataupun lisan dari orang-orang dan perilaku yang diamati. ${ }^{3}$ Penelitian ini dikata sebagai penelitian kualititaif karena data yang diperoleh oleh peneliti mengenai penggunaan kamus melalui lisan guru yang menjadi dosen Bahasa Arab di STAI As-Sunnah Medan,

sumber data pada penelitian ini yaitu dosen yang mengajar di bidang bahasa arab semester satu di STAI As-sunnah Medan. Untuk pengumpulan data maka penulis melakukan wawancara kepada dosen pengajar bahasa arab. Wawancara dilakukan dengan mengajuan pertanyaan secara langsung kepada subjek penelitian. Wawancara dapat dilakukan dengan cara tatap muka langsung atau dilakukan dengan memanfaatkan media komunikasi seperti, telpon, skype, dan lain-lain. ${ }^{4}$

Dalam penelitian peneliti menganalisis data yang didapat berdasarkan teori Miles dan Huberman, bahwa aktivitas dalam kualitatif dilakukan secara interaktif dan berlangsung secara terus menerus sampai tuntas, sehingga datanya sudah jenuh. Aktivitas dalam analisis data, yaitu data reduction, data display, dan conclusion drawing/verification. ${ }^{5}$

Penulis mencoba mendeskripsikan bagaimana pengunaan media pembelajaran berupa Kamus Musaid Al Arabiyah Baina Yadaik dalam konteks pembelajaran bahasa Arab dengan buku Al Arabiyah Baina Yadaik.

\section{HASIL DAN PEMBAHASAN}

\section{A. Kamus / mujam}

\section{Pengertian kamus / mujam}

kata قاموسyang dipinjam dari bahasa Yunani yang artinya adalah samudra atau lautan. Melalui penyesuain $q$ berubah $k$ "kamus"dapat diartikan sebagai buku acuan yang memuat daftar kosakata sedemikian banyak yang disusun berdasarkan abjad disertai keterangan tentang makna, pemakaian dan terjemahannya. ${ }^{6}$

Kamus Besar Bahasa Indonesia (KBBI) menjelaskan bahwa kamus merupakan buku yang didalamnya terdapat kosakata suatu bahasa yang tersususun secara alfabetis yang diikuti dengan penjelasan makna serta keterangan lainnya, diperuntukkan serta dilengkapi dengan contoh pemakaian entri dalam kalimat. selain

${ }^{2}$ Asep Saeful Hamdi dan E Baharuddin, Metode Penelitian Kualitataif Aplikasi Dalam Pendidikan (Yogyakarta: Deepublish, 2015), 5.

3 Iwan Hermawan, Metodologi Penelitian Pendidikan Kuantitatif, Kalitatif, Dan Mixed Metodh (Kuningan: Hidayatul Qur'an, 2019), 101.

4 Amir Hamzah, Metode Penelitian \& Pengembangan Researt \& Development (malang: CV Literasi Nusantara Abadi, 2019), 106. 321.

${ }^{5}$ Sugiono, Metode Penelitian Pendekatan Kuantitatif, Kualitatif, Dan R\&D (Bandung: Alfabeta, 2012),

${ }^{6}$ Izzan Ahmad, Metodologi Pembelajaran Bahasa Arab (Bandung: Humaniora, 2015), 190. 
itu kamus juga merupakan buku yang didalamnya terdapat istilah atau nama yang disusun berdasarkan abjada yang terdapat penejelasan makna dan pemakaiannya. ${ }^{7}$

\section{Macam-macam kamus}

hakim dan reza membedakan kamus menjadi 3 macam yaitu:

a. Kamus buku atau mu'jam Al-kitab

sistematika pembuatan kamus ini dirancang secara khusus untuk mengetahui makna kata yang terdpat dalam sebuah buku Dan disusun sesuai dengan tema yang ada pada buku.

b. Kamus digital

Yaitu, sebuah perangkat lunak computer (softwer) ang memuat program terjemah atau kamus Bahasa yang bisa diajalankan melalui media elektronik seperti computer, handphone, PDA dll.

c. Kamus On-line

Yaitu, program kamus secara yang bisa diaskes melalui internet. ${ }^{8}$

Dari macam-macam jenis kamus diatas penulis menyimpulkan bahwasa nya kamus musa'id lil kitab al-arabiyyah baina yadaik merupakan jenis kamus buku atau mu'jam al-kitab karena pembuatan kamus ini dikhususkan untuk memahami makna kata yang termuat dalam tema-tema materi pembelajaran dalam kita baina yadaik.

\section{Klasifkasi Kamus}

Menurut Abdulah Chaer jika Ditinjau dari aspek penggunaan bahasa, klasifikasi kamus dapat dikelompokan menjadi $3:^{9}$
a. Kamus eka bahasa
Dalam Kamus ini menggunakan satu bahasa. Bahasa yang dijelaskan didalamnya menggunakan kata yang sama dengan bahasa penjelasnya.
b. Kamus dwi bahasa
Kamus ini merupakan kamus berisikan daftar kata yang berasal dari bahasa tertentu yang penjelasannya dengan bahasa yang berbeda. Kamus
c. aneka bahasa
Dalam kamus ini terdapat daftar kosakata dengan keterangan tentang makna dan penejelasan yang ada di dalamnya terdapart lebih dari dua bahasa.
Jika dituinjau dari klarifi bahasanya kamus musa'id lil kitab baina yadaiak ini tergolong kedalam kamus dwi bahasa, karena kamus ini hanya terdiri dari dua bahasa didalamya yaitu bahasa Arab dan bahasa Indonesia.

\section{Fungsi kamus,}

Menurut chaer dalam jalam jurnal yang ditulis Dwi mawanti, dari segi tinjauan praktis dan teoritis fungsi kamus antara lain sebagai berikut: ${ }^{10}$

a. Mengetahui pelafalan suatu kata

\footnotetext{
${ }^{7}$ Galih Edy Nur widya Ningsih, Penggunaan kamus digital dan kamus cetak terhadap penguasaan Hanzi, jurnal ilmiah edukasi \& sosial, volume 10, no, 1. Maret 2019, 34-41

${ }^{8}$ Keswati, 'Pengembangan Kamus Bahasa Arab Untuk Buku Ta'lim Al-Lughah Al-'Arabiyah Sebagai Penunjang Buku Bahasa Arab Kelas VIII Madrasah Stanawiyah” (Universitas Negeri Semarang, 2014), 21.

${ }^{9}$ Besse Wahidah, "Kamus Bahasa Arab Sebagai Sumber Belajar (Kajian Terhadap Penggunaan Kamus Cetak Dan Kamus Digital)," At-Turast 11 (2017): 58-71.

${ }^{10}$ Dwi Mawanti, pengembangan kamus visual multi bahasa (Arab-Inggris-Indonesia Jawa) Untuk Paud (Pendidikan Anak Usia Dini) Berbasis Kearifan Lokal Jurnal penelitian 2014 h,17
} 
Ketika mencari informasi kata dari kamus tentu kita bisa juga menemukan cara melafalkan kata tersebut, terutama kata yang berasal dari bahasa asing. Sehingga tidak menimbulkan perbedaan arti

b. Mengetahui arti suatu kata

Terkadang dalam satu kata memiliki banyak arti, dengn kamus kita bisa mengetahui berbagai arti dari satu kata tersebut.

c. Memberikan petunjuk Ejaan Yang disempurnakan (EYD)

Dengan memanfaatkan kamus dapat mengetahui ejaan kata yang benar pada setiap kata. Sehingga bisa menghindari kesalahan dalam penulisan.

\section{B. Kamus Musaid Al Arabiyah Baina Yadaik}

Kamus Musaid Al Arabiyah Baina Yadaik mencakup 7.000 kata dalam bahasa Arab yang paling sering digunakan pada buku Al Arabiyah Baina Yadaik, kamus ini juga memberikan pelayanan kepada peserta didik dan pengajar dalam memahami pelajaran buku Al Arabiyah Baina Yadaik.

Penyusun kamus : Tim PKPBA

$\begin{array}{ll}\text { Penerbit } & \text { : PKPBA (Program Khusus Pengembangan Bahasa Arab) UIN } \\ & \text { Malang } \\ \text { Ukuran kamus } & : 11,5 \mathrm{~cm} \mathrm{x} 15,5 \mathrm{~cm} \\ \text { Cover } & : \text { menggunakan Soft Cover } \\ \text { Berat } & : 300 \text { Gram } \\ \text { Tebal } & : 260 \text { halaman }\end{array}$

\section{Media pembelajaran}

\section{Defenisi media pembelajaran}

Terdapat Banyak pengertian media pembelajaran yang didefenisikan oleh para ahli, tapi menurut terminologi kata media berasal dari Bahasa latin "medium" yang artiya adalah sebuah perantara, sedangan dalam bahasa Arab, media adalah perantara (wasilah) dari kominkator kepada komunikan. ${ }^{11}$

Media adalah suatu alat yang digunakan sebagi suatu sarana untuk menyampaikan pesan atau sebuah informasi dari sumber kepada penerima, media juga sebagai komponen dalam strategi yang berupa manusia, alat maupun bahan yang mengacu kepada kegiatan pembelajaran. ${ }^{12}$

media pembelajaran merupakan media yang berupa ceta atau visual, suara, ataupun gabungan dari keduanya dengan termasuk teknologi yang dijadikan perangkat keras yang bisa dimanfaatkan dalam proses pemelajaran yang dapat membantu siswa agar lebih aktif dalam kegiatan pembelajaran. ${ }^{13}$

Media pembelajaran dapat dipahami sebagai sesuatu yang dapat menyampaikan dan menyalurkan pesan dari sumber secara terencana sehingga tercipta lingkungan belajar yang kondusif di mana penerimanya dapat melakukan proses belajar secara lebih efektif dan efisien".

\footnotetext{
${ }^{11}$ Azhar Arsyad, Media Pembelajaran (Jakarta: Grafindo Persada, 2011), 3.

${ }^{12}$ Dindin Rizwanuddin, Bahasa Indonesia (Jakarta: UIN Press, 2015), 134.

${ }^{13}$ Novia Lestari, Media Pembelajara Berbasis Multimedia Intreaktif (Klaten: Lakeisha, 2020), 2.
} 
Dari berbagai defenisi yang diungkapkan di atas, maka penulis menyimpulkan bahwasannya media pembelajaran merupakan suatu alat alternatif yang bisa digunakan dalam menyampaikan pesan atau informasi yang dapat meningkatkan stimulus pada otak untuk befikir, dan menimbulkan kemauan serta merangsang perasaan pendengar ( peserta didik). Sehingga dapat menjadikan kegiatan pembelajaran menjadi lebih maksimal.

\section{Peranan dan fungsi media dalam pembelajaran}

Menurut Kemp \& Dayton media memenuhi tiga fungsi utama apabila media itu digunakan untuk perorangan, kelompok, atau kelompok yang besar jumlahnya yaitu: ${ }^{14}$

a. Memotivasi minat atau tindakan

b. Menyajikan informasi

c. Memberi intruksi.

Adapun syarat-syarat yang harus dipenuhi dalam membuat media pembelajaran adalah sebgai berikut: ${ }^{15}$

a. Raisonal, yakni sesuatu dengan akal dan mampu dipikirkan oleh penggunanya

b. Ilmiah, yakni sesuai dengan kaidah-kaidah ilmu pengetahuan

c. Ekonomis, yaitu sesuai dengan kemampuan pembiayaan sehingga lebih hemat dan efesien.

d. Praktis, yaitu dapat digunakan dalam kondisi praktis disekolah dan bersifat sederhanah.

\section{Penggunaan Media Kamus Musa'id Lil Kitab baina Yadaik}

Berdasarkan hasil dari wawancara yang peneliti lakukan kepada salah satu dosen bidang studi bahasa Arab (Nur Halimah, S.pd ) menjadikan kamus musa'id lil kitab alarabiyyah baina yadiak sebagai salah satu media pembelajaran bahasa Arab pada bidang study qiro'ah yang menggunakan buku Al Arabiyah Baina Yadaik, sdengan metode pembelajaran sebagai berikut:

1. Dosen memberikan tugas pribadi kepada setiap murid untuk membaca nash yang ada pada buku baina yadaik jilid 2 wahda Sembilan dengan tema Wasaillu Annaqli AlItishol Qodiyman Wa Haditsan,

2. para siswa diminta untuk memahami nash tersebut diasrama dengan mencari kosakata yang ada pada teks menggunakan kamus al'musaid lil kitab al-arobiyah baina yadaik

3. nash tersebut akan didiskusikan untuk pembelajaran berikutnya,

4. Pada saat jam pelajaran dosen mengecek tugas tersebut dengan meminta siswa untuk menjawab latihan yang ada pada buku sesuai dengan nash yang telah dibaca dan difahami.

5. Dosen mengajak siwa untuk mengoreksi jawaban mereka, dengan cara bertukar buku.

6. Dosen menayakan hasil setiap siswa kepada pengoreksi.

Dari hasil koreksian bersama-sama, diadapatkan bahwasannya Dengan menggunakan media pembelajaran tersebut ternyata siswa mampu memahami nash $90 \%$ sebelum dijelaskan oleh dosen, hal ini bisa dilihat dari hasil belajar siswa yang meningkat, hampir seluruh siswa mendapatkan nilai 100 .

${ }^{14}$ cecep kustandi dan daddy Darmawan, Pengembangan Media Pembelajaran (jakarta: kencana, 2020), 17.

\footnotetext{
${ }^{15}$ Dina Indriana, Ragam Alat Bantu Media Pengajaran (yogyakarta: Diva Press, 2011), 56.
} 
dari analisis tersebut dapat disimpulkan kamus ini sangat membantu dosen bidang studi bahasa Arab dalam menjelaskan pelajaran. Karena Kamus ini juga menyediakan kosa kata-kosa kata yang sulit yang terdapat tertera di dalam buku Al Arabiyah Baina Yadaik sehingga mempermudah mahasiswi semester satu STAI As Sunnah Medan dalam proses penerjemahan materi yang ada didalam kitab Baina Yadaik.

Dari hasil wawancara dan obeservasi peneliti merumuskan dampak positif penggunaan kamus ini pada pembelajaran bahasa Arab yang mengguakan kitab Baina Yadaik.

Adapun Positif dan negatif penggunaan kamus ini adalah :

Positif:

a. Kamus Musaid Al Arabiyah Baina Yadaik sangat lah membantu mahasiswi, terutama dalam pembelajaran buku Al Arabiyah Baina Yadaik, karena dengan adanya kamus ini mempermudah mahasiswi semester satu STAI As Sunnah Medan dalam mencari makna dan kosa kata baru yang belum diketahui.

b. Kamus Musaid Al Arabiyah Baina Yadaik dalam pembelajaran buku Al Arabiyah Baina Yadaik yaitu kosa kata yang dipaparkan di desain berdasarkan materi yang ada di buku Al Arabiyah Baina Yadaik.

c. Kamus yang berukuran mini dan praktis, sehingga memudahkan penguna untuk membawanya kemana-mana.

Negatif:

a. Penyusunan kosa kata yang terdapat pada Kamus Musaid Al Arabiyah Baina Yadaik ini, tidaklah berdasarkan abjad, atau huruf hijaiyah, sehingga sedikit sulit bagi mahasiswi semester satu STAI As Sunnah Medan dalam pencarian makna kosa kata.

b. Dan kamus ini juga tidak memuat seluruh kosa kata yang terdapat pada buku Al Arabiyah Baina Yadaik, hanya kosa kata inti dari setiap bab yang di bahas, hal ini terasa sulit bagi mahasiswi pemula yang baru mengenal bahasa Arab.

\section{KESIMPULAN}

Berdasarkan hasil wawancara yang diperoleh peneliti dari salah satu dosen bidang studi bahasa Arab, dan mahasiswi semester satu di STAI As Sunnah Medan, maka dapat di ambil kesimpulan bahwasanya penggunaan Kamus Musaid Al Arabiyah Baina Yadaik sebagai sumber media pembelajaran sangat membantu siswa dalam pembelajaran bahasa Arab di kelas. Dosen tidak lagi harus menjelaskan satu persatu kosa kata yang terdapat pada buku Al Arabiyah Baina Yadaik, melainkan mahasiswi belajar secara mandiri dalam menemukan kosa kata yang di anggap sulit dengan menggunakan Kamus Musaid Al Arabiyah Baina Yadaik. Hal ini di dukung dengan keunggulan yang di miliki Kamus Musaid Al Arabiyah Baina Yadaik yang salah sat unya memuat kosa kata bahasa Arab sesuai dengan pembelajaran bahasa Arab yang terdapat pada buku Al Arabiyah Baina Yadaik serta memuat kosa kata-kosa kata sulit yang ada di buku Al Arabiyah Baina Yadaik, sehingga mempermudah mahasiswi semester satu STAI As Sunnah Medan dalam menerjemahkannya dan kamus ini juga ringan, sehingga mudahkan pengguna untuk membawanya kemana saja.

Dalam setiap kamus pastilah memiliki kekurangan, adapun kekurangan yang terdapat pada Kamus Musaid Al Arabiyah Baina Yadaik ini, kosa kata yang tertera tidak sesuai 
dengan abjad, melainkan dengan tema perbab yang dibahas didalam penulisan buku $\mathrm{Al}$ Arabiyah Baina Yadaik,

Berdasarkan paparan di atas maka dapat dikatakan bahwa Kamus Musaid Al Arabiyah Baina Yadaik layak untuk di pakai sebagai media pembelajaran bahasa Arab mahasiswi semester satu STAI As Sunnah Medan khususnya pada pembelajaran buku Al Arabiyah Baina Yadaik karena di dalamnya mencakup informasi yang terdapat pada buku tersebut.

\section{DAFTAR PUSTAKA}

Ahmad, Izzan. Metodologi Pembelajaran Bahasa Arab. Bandung: Humaniora, 2015.

Arsyad, Azhar. Media Pembelajaran. Jakarta: Grafindo Persada, 2011.

Baharuddin, Asep Saeful Hamdi dan E. Metode Penelitian Kualitataif Aplikasi Dalam Pendidikan. Yogyakarta: Deepublish, 2015.

Darmawan, cecep kustandi dan daddy. Pengembangan Media Pembelajaran. jakarta: kencana, 2020.

Hamzah, Amir. Metode Penelitian \& Pengembangan Researt \& Development. malang: CV Literasi Nusantara Abadi, 2019.

Hermawan, Iwan. Metodologi Penelitian Pendidikan Kuantitatif, Kalitatif, Dan Mixed Metodh. Kuningan: Hidayatul Qur'an, 2019.

Indriana, Dina. Ragam Alat Bantu Media Pengajaran. yogyakarta: Diva Press, 2011.

Keswati. "Pengembangan Kamus Bahasa Arab Untuk Buku Ta'lim Al-Lughah Al-'Arabiyah Sebagai Penunjang Buku Bahasa Arab Kelas VIII Madrasah Stanawiyah.” Universitas Negeri Semarang, 2014.

Lestari, Novia. Media Pembelajara Berbasis Multimedia Intreaktif. Klaten: Lakeisha, 2020.

Makalalag, Muh Arif dan Eby Waskino. Pengembangan Media Pembelajaran Bahasa Arab. Padang: Balai Insan Cendekia Mandiri, 2020.

Rizwanuddin, Dindin. Bahasa Indonesia. Jakarta: UIN Press, 2015.

Sugiono. Metode Penelitian Pendekatan Kuantitatif, Kualitatif, Dan R\&D. Bandung: Alfabeta, 2012.

Wahidah, Besse. "Kamus Bahasa Arab Sebagai Sumber Belajar (Kajian Terhadap Penggunaan Kamus Cetak Dan Kamus Digital).” At-Turast 11 (2017): 58-71. 